\title{
Nutrition and mental performance
}

\author{
BY PETER J. ROGERS AND HELEN M. LLOYD \\ Consumer Sciences Department, Institute of Food Research, Earley Gate, Whiteknights Road, \\ Reading RG6 2EF
}

There is no doubt that nutritional status can have significant and sometimes profound effects on human mental performance (Table 1). This is evidenced by, for example, the consequences of chronic and severe food restriction (Smart, 1993), thiamin deficiency (Kanarek \& Marks-Kaufman, 1991), and Fe deficiency (Pollitt, 1987). Acute effects of food and fluid ingestion have also been described, and it is this area that is the main concern of the present review.

\section{ALCOHOL AND CAFFEINE}

The two dietary constituents which have been studied most extensively in relation to such acute effects are alcohol (Steele \& Josephs, 1990; Finnigan \& Hammersley, 1992) and caffeine (James, 1991; van der Stelt \& Snel, 1993). Both these substances produce their various effects on cognitive functioning primarily by direct (pharmacological) action on the central nervous system (CNS), although, for example, some of the consequences of long-term alcohol abuse depend on nutritional factors associated with excessive alcohol consumption (Kanarek \& Marks-Kaufman, 1991). Very broadly, alcohol and caffeine can be characterized as having respectively depressant and stimulant psychoactive

Table 1. Examples of nutritional variables known to affect mental performance*

\begin{tabular}{|c|c|c|}
\hline Variable & Established & Less-well established \\
\hline Food restriction & $\begin{array}{l}\text { Early life undernutrition } \\
\text { Chronic semi-starvation }\end{array}$ & $\begin{array}{l}\text { Dieting to lose weight } \\
\text { Short-term fasting (e.g. missing a } \\
\text { meal) }\end{array}$ \\
\hline \multicolumn{3}{|l|}{ Pre- $v$. postprandial state } \\
\hline $\begin{array}{l}\text { Dietary macronutrient } \\
\text { composition }\end{array}$ & & $\begin{array}{l}\text { Acute effects } \\
\text { Chronic effects }\end{array}$ \\
\hline Micronutrient deficiencies & $\begin{array}{l}\text { Thiamin (Wernicke-Korsakoff } \\
\text { syndrome) Fe }\end{array}$ & \\
\hline \multicolumn{3}{|l|}{ Phenylketonuria } \\
\hline Diabetes & Hypoglycaemia & Chronic effects \\
\hline Alcohol & $\begin{array}{l}\text { Acute intoxication } \\
\text { Chronic effects, including fetal } \\
\text { alcohol syndrome }\end{array}$ & \\
\hline $\begin{array}{l}\text { Caffeine and } \\
\text { caffeine withdrawal }\end{array}$ & & \\
\hline
\end{tabular}

* For sources, see text and Kanarek \& Marks-Kaufman (1991). 
effects, and at least under some circumstances caffeine can offset alcohol-induced performance deficits (Hasenfratz et al. 1993).

A difficulty in interpreting the outcomes of studies on caffeine, however, is that this substance is consumed both widely and very frequently, and cessation of consumption is accompanied in many regular users by adverse changes such as increased incidence of headache, drowsiness and fatigue (James, 1991). Indeed, some of the studies on the withdrawal effects of caffeine are similar in design to many of the studies purporting to show improved mood and/or performance efficiency following administration of caffeine. A typical procedure is to compare the effects of caffeine and a placebo in caffeine-deprived subjects (e.g. Clubley et al. 1979; Bruce et al. 1986; Lieberman et al. 1987). The problem with this approach is that it leaves open the question as to whether the findings are due to beneficial effects of caffeine or to deleterious effects of caffeine deprivation (or a combination of both of these).

Surprisingly, this issue has received very little attention. The effects of caffeine in non-users of caffeine (i.e. in individuals who do not regularly consume coffee, tea, cola etc.) have not been examined in detail, perhaps partly because of the ethical questions this raises. In any case, differences between the responses to caffeine of users and non-users of caffeine could be due to a number of factors. For example, caffeine users were found to score higher than non-users on measures of addiction, extraversion and impulsivity (Eysenck Personality Scales; Eysenck \& Eysenck, 1991; N. J. Richardson \& P. J. Rogers, unpublished results). Other results show that on certain tasks high impulsives, assumed to have a relatively low level of endogenous arousal, benefit more from the performance-enhancing effects of caffeine than do low impulsives (Smith et al. 1991). There is also a strong relationship between the level of use and the pharmacokinetics of caffeine, which has been interpreted as indicating that users absorb caffeine more efficiently than non-users (Kuznicki \& Turner, 1986). Another approach, which again has been used only very rarely, is to test the effects of caffeine in users who have been 'fully' withdrawn from caffeine. This requires subjects to be deprived of caffeine for a minimum of 1 week and preferably longer (Griffiths \& Woodson, 1988). Bruce et al. (1991) found increased tiredness in caffeine users deprived of caffeine for $24 \mathrm{~h}$ compared with users deprived for $7 \mathrm{~d}$. The $24 \mathrm{~h}$ group also showed a more rapid decline in performance on a simple tapping task. When the subjects were given caffeine this reduced (compared with placebo) tiredness and also headache only in the $24 \mathrm{~h}$ group. Since very high doses ( 250 and $500 \mathrm{mg}$ ) were administered, it is unlikely that altered caffeine pharmacokinetics alone can account for the lack of significant effects of caffeine in the $7 \mathrm{~d}$-deprived group.

Of course such findings by no means exclude the possibility that there is a net benefit to be derived from the regular use of caffeine. Indeed, there is good evidence that caffeine can improve absolute levels of cognitive performance. In particular, it appears to be effective in counteracting deteriorated performance. Examples of this are findings indicating that caffeine has stronger performance-improving effects in older than younger adults (Jarvis, 1993), and that caffeine can offset certain aspects of the 'post-lunch dip' in mental performance (Smith et al. 1991) and drug-induced impairments in performance efficiency (e.g. File et al. 1982). Nonetheless, some of the benefits experienced following the consumption of caffeine are probably more apparent than real because these effects involve the reversal of the deleterious consequences of caffeine deprivation, for instance, those that occur after overnight withdrawal (Rogers \& 
Richardson, 1993; N. J. Richardson \& P. J. Rogers, unpublished observations). In order to assess the net benefit of the everyday use of caffeine it will be necessary to carry out further investigations where the psychoactive effects of caffeine are evaluated in relation to caffeine withdrawal, and using dose levels and a pattern of administration which model 'real' behaviour more closely.

\section{BREAKFAST, LUNCH AND MEAL COMPOSITION}

The effects of meals on cognitive efficiency have been recently reviewed in detail by Smith \& Kendrick (1992). Relatively little work has been carried out in this area, although some of the earliest studies were reported over 40 years ago. A common finding is that performance is impaired in the early afternoon compared with performance measured in the late morning (the so-called post-lunch dip). For some tasks this occurs whether or not lunch has been eaten, although consuming a meal at lunchtime, particularly if this is a large meal, does appear to contribute significantly to the post-lunch dip. Tasks which are most typically affected are those requiring sustained attention (Smith \& Kendrick, 1992). There is, however, a problem concerning the interpretation of results showing impairments when no lunch is eaten, which might indicate effects related either to fasting or to an underlying circadian variation in, for example, alertness. If the latter were responsible, performance would be expected to recover later in the afternoon. Unfortunately, repeated assessment of performance efficiency, by introducing fatigue or practice effects, may itself influence the outcome of the experiment. Additionally, it is important to note that post-lunch impairments in performance are by no means always observed. In particular, several results suggest that meals consumed at lunchtime have least effect on performance efficiency under conditions of high arousal; for instance, when subjects are given caffeine (see p. 444), or when they are exposed to a high level of background noise (Smith \& Miles, 1986). The effects of lunch on performance also appear to be quite strongly related to personality factors such as extraversion and neuroticism (Craig et al. 1981; Smith \& Miles, 1986).

In contrast to the effects of lunch, there is a popular belief that missing breakfast can have an adverse effect on cognitive efficiency. When taken together, however, the published experimental evidence does not substantially support this belief. A series of studies conducted by Tuttle and colleagues (for review, see Editorial, 1957; Smith \& Kendrick, 1992) indicated somewhat poorer reaction-time performance in subjects who had not been given breakfast, and recently a similar result has been reported for memory performance (Benton \& Sargent, 1992). In addition, 9-11-year-old children were found to score significantly less well on a problem-solving task (matching familiar figures test) when tested in the morning following an overnight fast compared with when they were tested following breakfast (Pollitt et al. 1981, 1983). This latter work has received a considerable amount of attention, but the finding of a detrimental effect of missing breakfast should be viewed in the context of other studies where this was not observed (e.g. Dickie \& Bender, 1982; Smith \& Kendrick, 1992). Also, given the fairly long period of food restriction imposed in the experiments by Pollitt et al. 1981, 1983; (the children were tested either 3 or $18 \mathrm{~h}$ after their last meal), it could be argued reasonably that the lack of more substantial effects indicates that cognitive performance is relatively invulnerable to short-term fasting. In fact, of the various measures of performance taken, only one showed a statistically significant deterioration related to missing 
breakfast, while one other (frequency of recall of the last item on a test of immediate memory) showed a small but significant improvement (Pollitt et al. 1981).

Very little information is available on the effects of meals eaten at other times of the day. However, there has been more interest in the influence of meal composition on cognitive performance. This is because of certain theoretical predictions concerning the proposal that the proportion of protein relative to carbohydrate in a meal can modify the ratio of the plasma concentration of tryptophan to the other large neutral amino acids (Trp: 2 LNAA), and thereby alter brain tryptophan uptake, brain serotonin synthesis and serotoninergic function (Fernstrom \& Wurtman, 1972; Wurtman et al. 1981; Fernstrom, 1994; Fernstrom \& Fernstrom, 1994). The behavioural consequences which have been hypothesized to follow from these meal-induced changes in neurotransmission include altered food choice and food intake, and changes in pain sensitivity, aggressiveness, mood, alertness and cognitive performance. Accordingly, the relative increase in brain serotoninergic activity that supposedly follows the consumption of a high-carbohydrate $v$. a high-protein meal can be expected to give rise to a decrease in alertness and an increase in sleepiness, and consequently a fall-off in performance efficiency (for reviews, see Spring et al. 1987; Young, 1991). Although the evidence is not strong, where differences have been found, these were in the direction of poorer performance after a high-carbohydrate compared with a high-protein meal (Spring et al. 1983; Lieberman et al. 1986b). Reaction time and tasks requiring sustained attention were most affected. Nonetheless, even in these studies, a large majority of the comparisons between subject groups or performance measures failed to reveal statistically significant effects of meal composition. In addition, administration of tryptophan alone was found to have only a marginal effect on one (simple auditory reaction time) of four tests of performance, despite the fact that the dose used, approximately $3.5 \mathrm{~g}$, was sufficient to produce a number of measurable subjective changes, including decreased alertness and vigour, and increased fatigue (Lieberman et al. 1983; Hrboticky et al. 1985; Spring et al. 1987).

A further difficulty for the proposed relationships between the protein-carbohydrate content of a meal and mood and performance, is that the observations relating brain serotonin and meal composition have been obtained from studies on rats, not humans. Studies on humans have shown statistically significant differences in plasma Trp: 2 LNAA values following 'meals' of starch, sugar and protein, but it appears that the magnitude of these effects is probably too small to produce functionally significant changes in brain serotoninergic activity (Leathwood, 1987; Young, 1991). The actual changes observed were small increases in plasma Trp: $L$ LNAA following starch and sugar meals and a larger decrease in this ratio after high-protein meals. Differences in Trp: $\Sigma$ LNAA did not reach their maximum until $2-3 \mathrm{~h}$ after these meals, with almost no change occurring within the first hour after a carbohydrate meal (e.g. Lieberman et al. 1986a; Christensen \& Redig, 1993). In the latter study there were no corresponding effects on mood and alertness. Also, meals which are more typical in composition are unlikely to produce any distinct differences in postprandial Trp: $\Sigma$ LNAA values, since the presence of a small amount (perhaps as little as $4 \%$ energy) of protein in a high-carbohydrate meal is sufficient to block any meal-induced increases in plasma Trp: $\mathrm{L}$ LNAA (Leathwood, 1987; Teff et al. 1989; Wurtman \& Wurtman, 1992; Christensen \& Redig, 1993).

Other studies examining the effects of meal composition include an investigation by Smith et al. (1988) who found that isoenergetic, high-carbohydrate and high-protein meals affected different aspects of attention. However, because the high-carbohydrate 


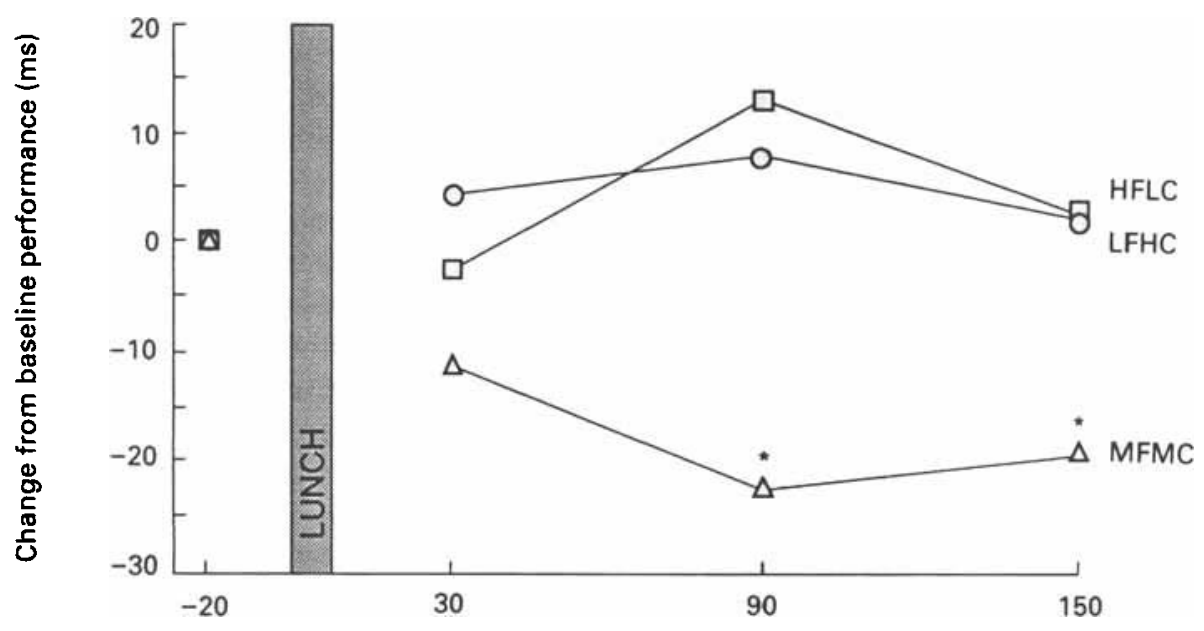

Time-interval before start and after end of lunch ( $\mathrm{min})$

Fig. 1. Changes in simple reaction-time performance following isoenergetic ( $2.93 \mathrm{MJ}$ ( 700 kcal)) lunches differing in fat and carbohydrate content. Baseline measures were taken 20 min before lunch $(-20)$. (O), low-fat ( $29 \%$ energy), high-carbohydrate (55\% energy) meal (LFHC); $(\triangle)$, medium-fat ( $45 \%$ energy), medium-carbohydrate ( $42 \%$ energy) meal; $(\square)$, high-fat ( $62 \%$ energy), low-carbohydrate ( $24 \%$ energy) meal (HFLC). Mean values were significantly different from those for LFHC and HFLC: *P<0 05. Adapted from Lloyd et al. (1994).

meals contained $15 \%$ energy from protein and testing began within $1 \mathrm{~h}$ after lunch it is very unlikely that this dissociation was mediated by differences in Trp: 2 LNAA. Moreover this mechanism can not account for recent results showing poorer reactiontime performance and lower alertness following isoenergetic lunchtime meals high in fat or high in carbohydrate compared with a meal containing intermediate levels of fat and carbohydrate (Lloyd et al. 1994). The findings for reaction time are presented in Fig. 1, which shows that the different effects of the three lunches were present to a moderate degree within $30 \mathrm{~min}$ of finishing the meal. At this time there were also differences in mood, including significantly greater 'drowsiness' following the high-fat and highcarbohydrate meals. On the other hand, several other measures of mood and performance (e.g. immediate recall, rapid information processing) were unaffected by meal composition. A further observation was that the medium-fat, medium-carbohydrate meal contained proportions of fat, carbohydrate and protein similar to those of the lunches usually eaten by the subjects. Perhaps, therefore, postprandial effects on mood and performance are a factor influencing food choice (and liking), such that choices producing desired effects are more likely to be repeated on future occasions (Booth, 1978; Rogers et al. 1992; Rogers \& Richardson, 1993). This suggestion is supported by the results of a second study in which subjects' mood and performance were assessed in the morning following breakfasts containing different proportions of fat and carbohydrate. Again, optimal effects were seen after the meal with the macronutrient composition which most closely matched that normally consumed by these subjects at breakfast; in this instance, however, this was the meal having the highest carbohydrate and lowest fat content (62 and $28 \%$ energy respectively; H. M. Lloyd, unpublished results). 
An important aspect of these last two studies was that the meals did not differ significantly (as measured by subjects' ratings) in appearance or orosensory qualities. For example, each of the three lunches consisted of a cheese and salad sandwich and a strawberry milk shake. Fat and carbohydrate content were manipulated by using low-fat cheese and spread and adding either cream or maltodextrin to the milk shake as appropriate (Lloyd et al. 1994). Clearly, if meal appearance, taste and other variables are not controlled, the effects of these variables, perhaps due to subjects' expectations, may be confounded with the effects of nutrient composition. Unfortunately, it is very difficult to alter the protein:carbohydrate value of a meal to any substantial extent without also altering its orosensory qualities, and typically there has been no attempt to disguise this manipulation. For instance, in the study carried out by Lieberman et al. (1983) subjects were provided with a meal consisting of either trimmed turkey breast (high-protein meal) or non-dairy sherbet (sorbet; high-carbohydrate meal). Similarly, the emotional impact and expectations arising from missing a meal, or being given an obviously much larger or smaller meal than usual, makes it difficult to draw unambiguous conclusions about the nutritional effects on mood and performance of these manipulations (Brooke, 1973).

There is, nonetheless, a measure of agreement in the findings from this work. For instance, although alertness tends to be increased and performance efficiency improved following a high-carbohydrate breakfast, meals with a high-carbohydrate content eaten at lunch have, if anything, the opposite effect (Lieberman et al. 1983; Lloyd et al. 1994; Wells \& Read, 1994; H. M. Lloyd, unpublished results). The appearance of certain mood and performance effects within $0.5 \mathrm{~h}$ of eating suggests that pre-absorptive and/or early post-absorptive mechanisms are implicated. At present, however, the nature of these mechanisms is unclear. Indeed, it is difficult to be more specific than suggesting, for example, that many of the effects following lunch are consistent with a postprandial increase in parasympathetic activity. One study, though, has demonstrated substantial, dose-related effects of intravenously administered cholecystokinin (CCK) on alertness and performance (Stacher et al. 1979). This is of particular interest because fat and protein are more potent releasers of CCK than carbohydrate (Liddle et al. 1983). Therefore, CCK may provide part of a mechanism mediating effects of meal composition as well as meal size. In addition, adaptation of the gastrointestinal and other physiological responses to food associated with medium- to longer-term changes in diet composition (e.g. Cunningham et al. 1991) suggests that the behavioural effects of food can also be expected to vary as a function of individual dietary history. An implication of this is that, as well as exploring the mechanisms underlying the effects of meals on mood and performance, a priority for studies in the future is the investigation of the consequences of longer-term dietary changes.

\section{EFFECTS OF GLUCOSE DRINKS}

Table 2 summarizes the results of thirteen experiments which investigated the effects of glucose drinks on cognitive performance. Eight of these experiments revealed a significant difference between the effects of a glucose drink compared with.a 'placebo' drink on at least one measure of performance. With one exception the differences were in the direction of better performance after the glucose drink. (The study by Brooke \& Toogood (1973) is included on the assumption that their results reflect an effect on mainly cognitive rather than physical performance.) A clear finding is that the effects on 


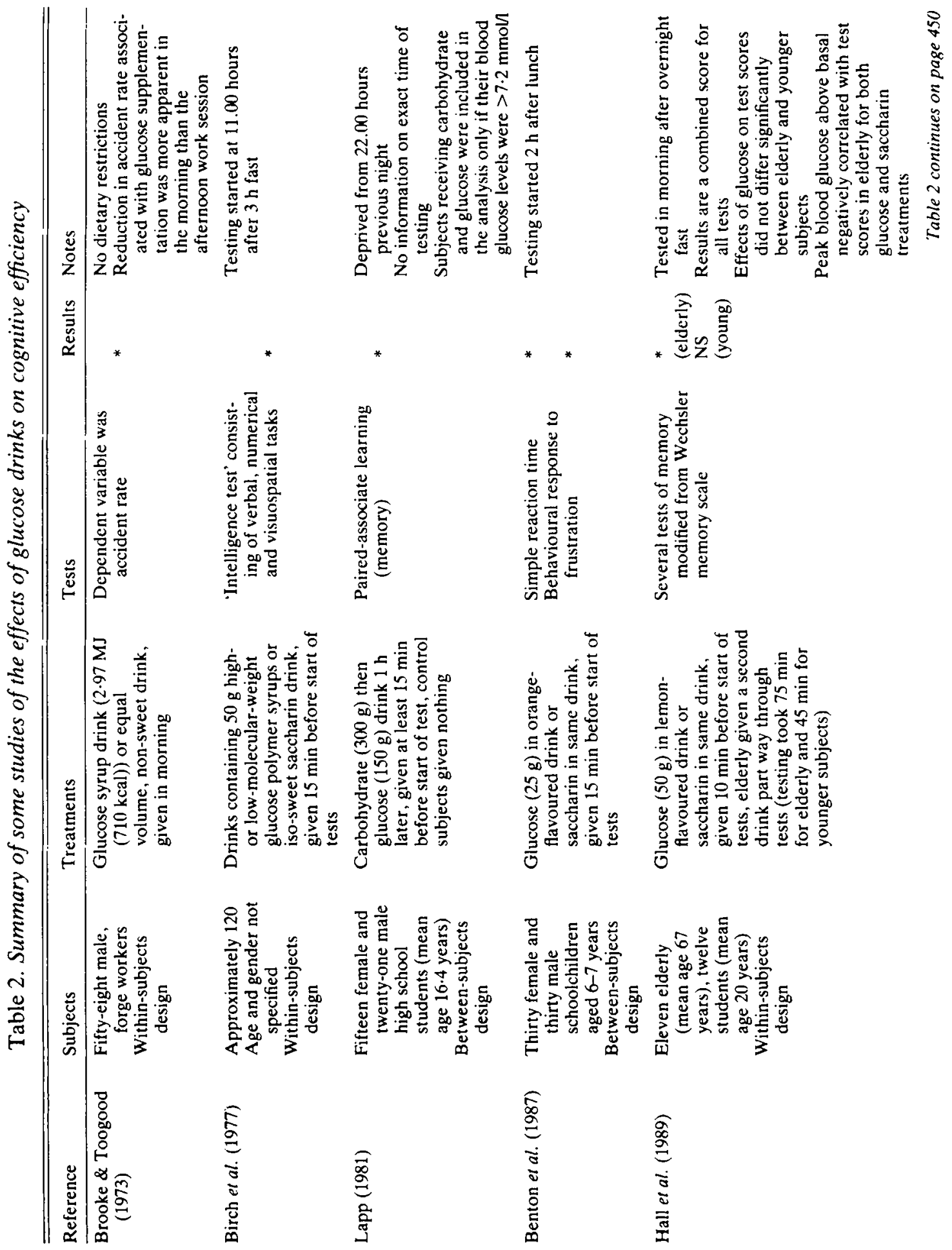




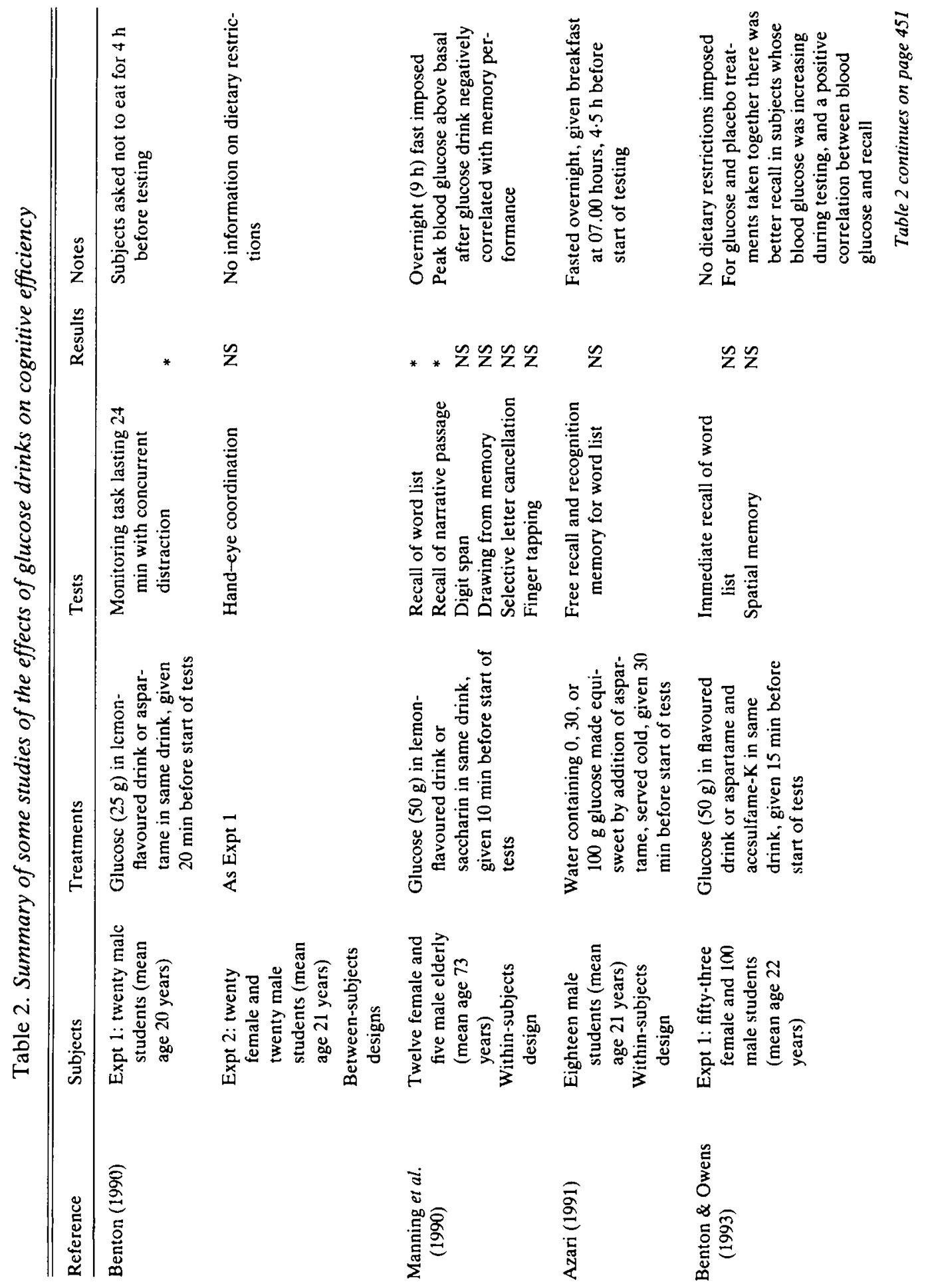



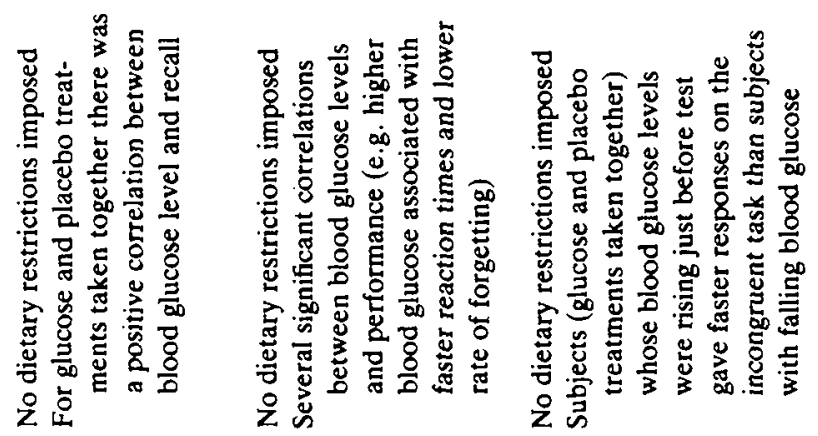

Z

, 年

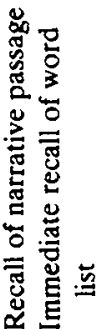
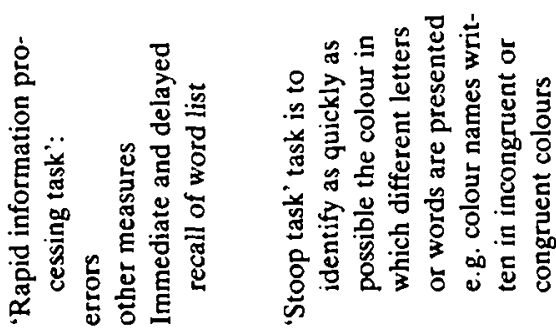

戠离

氖是员

壱宁总。

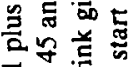

袁总苟总

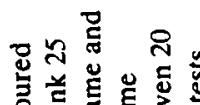

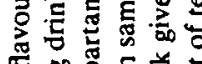

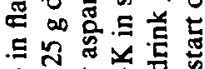

कि

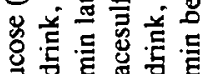

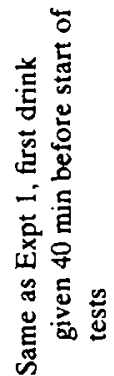

总营

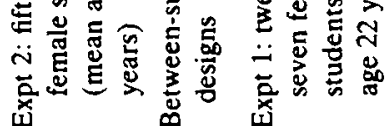
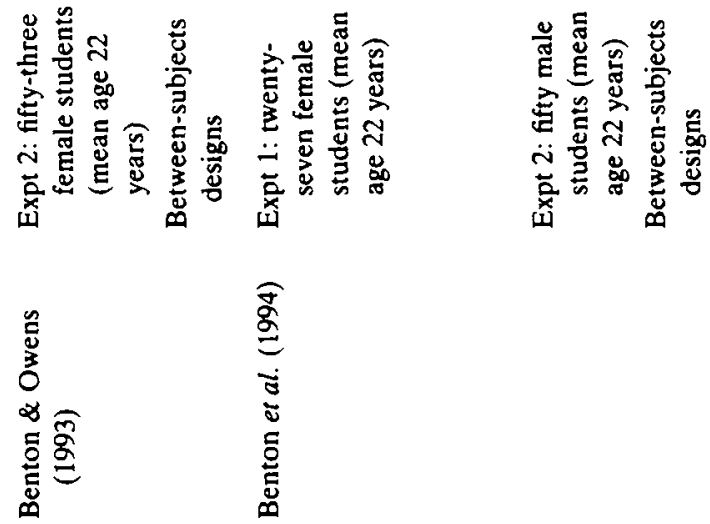
performance occurred within $1 \mathrm{~h}$ and often sooner after the drink was consumed. Furthermore, these effects were observed in fasted and non-fasted (i.e. last food $\leq 4 \mathrm{~h}$ before testing) subjects. Table 2 also shows that the tests on young adults yielded relatively few significant results. Overall, however, there is no apparent pattern to the aspects of performance or types of task affected. In addition to these results, Siebert et al. (1986) reviewed several papers published in German which report significantly improved performance following consumption of glucose drinks. Vigilance (i.e. sustained attention), in particular, was found to be improved. One experiment, for example, showed that when subjects were given glucose they made very few errors in a simulated driving task, whereas their performance when given a placebo deteriorated markedly towards the end of the test (Keul et al. 1982). Finally, there is at least one other report finding little or no improvement in performance following a glucose drink (Horton \& Yates, 1987). This study is noteworthy because subjects with high and low dietary intakes of sugar were compared, although unfortunately a placebo test was not included in the experimental design.

A stimulus for some of the more recent studies in this series was provided by findings showing that glucose administration can enhance learning and memory performance in rats (e.g. Gold, 1986). This, together with other evidence, has been used to support the suggestion that the effects of cognition-enhancing drugs (nootropics) are mediated primarily by the stimulation of increases in blood glucose levels and in turn increased uptake and utilization of glucose by the brain (Wenk, 1989). There can be no doubt that starving the brain of glucose has severe effects; however, it is much less clear that raising blood glucose above the normal fasting or premeal levels recorded in the studies in Table 2 (i.e. not less than $4.5 \mathrm{mmol} / \mathrm{l}$ ) will have a significant impact on cerebral metabolism. Lowering blood glucose leads rapidly to a substantial deterioration in cognitive performance, but typically this is observed only once the level has fallen to below about $3 \mathrm{mmol} / 1$ (e.g. Pramming et al. 1986; Richardson, 1990; Amiel, 1994). Therefore, hypoglycaemia sufficient to cause cognitive dysfunction would not normally be expected to occur in healthy individuals. In other words, under most circumstances improvement in performance following the consumption of a glucose drink, or after eating a meal or snack (see p. 445 , p. 448 and Kanarek \& Swinney, 1990), is unlikely to be due to any major alteration in the supply of glucose to the brain.

A further result reported in some of the studies summarized in Table 2 was that blood glucose levels or changes in blood glucose levels correlated significantly with one or more measures of performance. These observations have also been used to support the view that beneficial effects of glucose administration are due to direct effects on brain functioning (e.g. Benton \& Owens, 1993; Benton et al. 1994; see also Benton \& Sargent, 1992). Other aspects of the results, however, suggest an indirect relationship. For instance, positive correlations between performance and blood glucose levels measured before glucose administration, and also between performance and changes in blood glucose levels, were found both in the absence of a significant beneficial effect of the glucose drink and irrespective of which drink (glucose or placebo) the subjects had received. That is, the effect of the drink on blood glucose did not reliably predict performance and, at least from these studies, the conclusion must be that there is no enhancement of performance by glucose per se. Perhaps the most reasonable interpretation of the reported correlations is that high baseline levels of blood glucose or rapidly rising levels of blood glucose reflected increased sympathetic activity, including increased 
secretion of adrenalin and cortisol, which in turn benefited performance. Although the physiological interactions which underlie this correlation between arousal (alertness) and performance (Johnson et al. 1992) may well include increased glucose uptake and utilization by the CNS (Wenk, 1989), there is no firm evidence that this is the mechanism which is primarily responsible for the performance-enhancing effects of stress, or the administration of either glucose or nootropic drugs.

\section{CONCLUSIONS}

The studies reviewed here have demonstrated acute effects on cognitive performance of certain dietary manipulations with varying degrees of relevance to everyday eating habits. Caffeine is consumed widely and frequently and has clear effects on performance, although certain results may have exaggerated the benefits of caffeine use because the possible negative consequences of caffeine withdrawal were not taken into account. Indeed, there is perhaps a more general tendency to overestimate the importance of the effects revealed by studies in this field, due in large part to the inclusion of multiple tests and multiple measures of performance. This arises because of a failure to define hypotheses predicting specific performance effects. As a result, undue weight is often given to measures revealing statistically significant effects, with little discussion of areas of performance which are unaffected. This bias is probably also compounded by the failure to report experiments which do not find any significant treatment effects. The paper by Azari (1991) is a notable exception in this respect. There is, nonetheless, accumulating evidence that meal size and meal composition can influence postprandial performance efficiency, although their exact impact is modified by a variety of factors including time-of-day and other contextual variables. In particular, effects are most evident under low levels of arousal. This is important because often the testing procedures used are mildly stressful and, therefore, may interfere with the very phenomena they are designed to measure. Finally, there is also a need for further investigation of the physiological mechanisms mediating the performance and mood effects of foods. In the case of carbohydrates the proposed mechanisms and predicted effects will differ according to whether performance is measured within the first $0.5 \mathrm{~h}$ after the 'meal', or after 7 or more hours. To date, however, most experimental studies have included performance assessments at intervals relevant to only one of these time-points.

The authors thank Pauline Jas for her helpful comments on an earlier draft of this paper.

\section{REFERENCES}

Amiel, S. A. (1994). Nutrition of the brain: macronutrient supply. Proceedings of the Nutrition Society 53, $401-405$.

Azari, N. P. (1991). Effects of glucose on memory processes in young adults. Psychopharmacology 105, 521-524.

Benton, D. (1990). The impact of increasing blood glucose on psychological functioning. Biological Psychology 30, 13-19.

Benton, D., Brett, V. \& Brain, P. F. (1987). Glucose improves attention and reaction to frustration in children. Biological Psychology 24, 95-100.

Benton, D. \& Owens, D. S. (1993). Blood glucose and human memory. Psychopharmacology 113, 83-88.

Benton, D., Owens, D. S. \& Parker, P. Y. (1994). Blood glucose influences memory and attention in young adults. Neuropsychologia (In the Press). 
Benton, D. \& Sargent, J. (1992). Breakfast, blood glucose and memory. Biological Psychology 33, 207-210.

Birch, G. G., Cowell, N. D. \& Charles, G. A. (1977). Effects of dietary carbohydrate on intellectual performance. Proceedings of the Nutrition Society 36, 25A.

Booth, D. A. (1978). Acquired behavior controlling energy intake and output. Psychiatric Clinics of North America 1, 545-579.

Brooke, J. D. (1973). Carbohydrates and human performance. In Molecular Structure and Function of Food Carbohydrate, pp. 235-261 [G. G. Birch and L. F. Green, editors]. Barking: Applied Science Publishers.

Brooke, J. D. \& Toogood, S. (1973). Factory accidents and carbohydrate supplements. Proceedings of the Nutrition Society 32, 94A-95A.

Bruce, M., Scott, N., Lader, M. \& Marks, V. (1986). The psychopharmacological and electrophysiological effects of single doses of caffeine in healthy human subjects. British Journal of Clinical Pharmacology 22, $81-87$.

Bruce, M., Scott, N., Shine, P. \& Lader, M. (1991). Caffeine withdrawal: a contrast of withdrawal symptoms in normal subjects who have abstained from caffeine for 24 hours and for 7 days. Journal of Psychopharmacology 5, 129-134.

Christensen, L. \& Redig, C. (1993). Effect of meal composition on mood. Behavioral Neuroscience 107, 346-353.

Clubley, M., Bye, C. E., Henson, T. A., Peck, A. W. \& Riddington, C. J. (1979). Effects of caffeine and cyclizine alone and in combination on human performance, subjective effects and EEG activity. British Journal of Clinical Pharmacology 7, 157-163.

Craig, A., Baer, K. \& Diekmann, A. (1981). The effects of lunch on sensory-perceptual functioning in man. International Archives of Occupational and Environmental Health 49, 105-114.

Cunningham, K. M., Daly, J., Horowitz, M. \& Read, N. W. (1991). Gastrointestinal adaptation to diets of differing fat composition in human volunteers. Gut 32, 483-486.

Dickie, N. H. \& Bender, A. E. (1982). Breakfast and performance in schoolchildren. British Journal of Nutrition 48, 483-496.

Editorial (1957). Physiologic results of breakfast habits. Nutrition Reviews 15, 196-198.

Eysenck, H. J. \& Eysenck, S. B. G. (1991). Manual of the Eysenck Personality Scales (EPS Adult). London: Hodder and Stoughton.

Fernstrom, J. D. (1994). The effect of dietary macronutrients on brain serotonin formation. In Appetite and Body Weight Regulation, Sugar, Fat, and Macronutrient Substitutes, pp. 51-62 [J. D. Fernstrom and G. D. Miller, editors]. Boca Raton: CRC Press.

Fernstrom, J. D. \& Fernstrom, M. H. (1994). Dietary effects on tyrosine availability and catecholamine synthesis in the central nervous system: possible relevance to the control of protein intake. Proceedings of the Nutrition Society 53, 419-429.

Fernstrom, J. D. \& Wurtman, R. J. (1972). Brain serotonin content: physiological dependence on plasma tryptophan levels. Science 173, 149-151.

File, S. E., Bond, A. J. \& Lister, R. G. (1982). Interaction between effects of caffeine and lorazepam in performance tests and self-ratings. Journal of Clinical Psychopharmacology 2, 102-106.

Finnigan, F. \& Hammersley, R. (1992). The effects of alcohol on performance. In Handbook of Human Performance, vol. 2, Health and Performance, pp. 73-126 [A. P. Smith and D. M. Jones, editors]. London: Academic Press.

Gold, P. E. (1986). Glucose modulation of memory storage processing. Behavioral and Neural Biology 45, 342-349.

Griffiths, R. R. \& Woodson, P. P. (1988). Caffeine and physical dependence: a review of human and laboratory animal studies. Psychopharmacology 94, 437-451.

Hall, J. L., Gonder-Frederick, L. A., Chewning, W. W., Silveira, J. \& Gold, P. E. (1989). Glucose enhancement of performance on memory tests in young and aged humans. Neuropsychologia 27, 1129-1138.

Hasenfratz, M., Bunge, A., Dal Prá, G. \& Bättig, K. (1993). Antagonistic effects of caffeine and alcohol on mental performance parameters. Pharmacology, Biochemistry and Behavior 46, 463-465.

Horton, J. R. \& Yates, A. J. (1987). The effects of long-term high and low refined-sugar intake on blood glucose regulation, mood, bodily symptoms and cognitive functioning. Behaviour Research and Therapy 25 , $57-66$.

Hrboticky, K., Leiter, L. A. \& Anderson, G. H. (1985). Effects of L-tryptophan on short term food intake in lean men. Nutrition Research 5, 595-607.

James, J. E. (1991). Caffeine and Health. London: Academic Press. 
Jarvis, M. (1993). Does caffeine intake enhance absolute levels of cognitive performance? Psychopharmacology 110, 45-52.

Johnson, E. O., Kamilaris, T. C., Chrousos, G. P. \& Gold, P. W. (1992). Mechanisms of stress: a dynamic overview of hormonal and behavioral homeostasis. Neuroscience and Biobehavioral Reviews 16, 115-130.

Kanarek, R. B. \& Marks-Kaufman, R. (1991). Nutrition and Behavior: New Perspectives. New York: Van Nostrand Reinhold.

Kanarek, R. B. \& Swinney, D. (1990). Effects of food snacks on cognitive performance in male college students. Appetite 14, 14-27.

Keul, J., Huber, G., Lehmann, M., Berg, A. \& Jakob, E.-F. (1982). Einfiuss von Dextrose auf Fahrleistung, Konzentrationsfähigkeit, Kreislauf und Stoffwechsel im Kraftfahrzeug-Simulator (Doppleblind-Studie im Cross-over design) (Effects of dextrose on driving ability, concentration, circulation and metabolism measured in a driving simulator (double-blind study using a cross-over design)). Aktuelle ErnährungsMedizin 7, 7-14.

Kuznicki, J. T. \& Turner, L. S. (1986). The effects of caffeine on caffeine users and non-users. Physiology and Behavior 37, 397-408.

Lapp, J. E. (1981). Effects of glycemic alterations and noun imagery on the learning of paired associates. Journal of Learning Disabilities 14, 35-38.

Leathwood, P. D. (1987). Tryptophan availability and serotonin synthesis. Proceedings of the Nutrition Society 46, 143-156.

Liddle, R. A., Goldfine, I. D. \& Williams, J. A. (1983). Bioassay of circulating CCK in rat and human plasma. Gastroenterology 84, 1231-1236.

Lieberman, H. R., Caballero, B. \& Finer, N. (1986a). The composition of lunch determines afternoon plasma tryptophan ratios in humans. Journal of Neural Transmission 65, 211-217.

Lieberman, H. R., Corkin, S., Spring, B. J., Growden, J. H. \& Wurtman, R. J. (1983). Mood, performance, and pain sensitivity: changes induced by food constituents. Journal of Psychiatric Research 17, $135-145$.

Lieberman, H. R., Spring, B. \& Garfield, G. S. (1986b). The behavioral effects of food constitutents: strategies used in studies of amino acids, protein, carbohydrate and caffeine. Nutrition Reviews $\mathbf{4 4}$ (Suppl.), $61-69$.

Lieberman, H. R., Wurtman, R. J., Emde, G. C., Roberts, C. \& Coviella, I. L. G. (1987). The effects of low doses of caffeine on human performance and mood. Psychopharmacology 92, 308-312.

Lloyd, H. M., Green, M. W. \& Rogers, P. J. (1994). Effects of iso-caloric lunches differing in fat and carbohydrate content on cognitive performance and mood. Physiology and Behavior (In the Press).

Manning, C. A., Hall, J. L. \& Gold, P. E. (1990). Glucose effects on memory and other neuropsychological tests in elderly humans. Psychological Science 1, 307-311.

Pollitt, E. (1987). Effects of iron deficiency on mental development: methodological considerations and substantive findings. In Nutritional Anthropology, pp. 225-254 [F. E. Johnson, editor]. New York: Alan R. Liss.

Pollitt, E., Leibel, R. L. \& Greenfield, D. (1981). Brief fasting, stress, and cognition in children. American Journal of Clinical Nutrition 34, 1526-1533.

Pollitt, E., Lewis, N. L., Garza, C. \& Shulman, R. J. (1983). Fasting and cognitive function. Journal of Psychiatric Research 17, 169-174.

Pramming, S., Thorsteinsson, B., Theilgaard, A., Pinner, E. M. \& Binder, C. (1986). Cognitive function during hypoglycaemia in type I diabetes mellitus. British Medical Journal 292, 647-650.

Richardson, J. T. (1990). Cognitive function in diabetes mellitus. Neuroscience and Biobehavioral Reviews 14, 385-388.

Kogers, P. J., Edwards, S., Green, M. W. \& Jas, P. (1992). Nutritional influences on mood and cognitive performance: the menstrual cycle, caffeine and dieting. Proceedings of the Nutrition Society 51, 343-351.

Rogers, P. J. \& Richardson, N. J. (1993). Why do we like drinks that contain caffeine? Trends in Food Science and Technology 4, 108-111.

Siebert, G., Gessner, B. \& Klasser, M. (1986). Energy supply of the central nervous system. Bibliotheca Nutritio et Dieta 38, 1-26.

Smart, J. L. (1993). 'Malnutrition, learning and behaviour': 25 years on from the MIT symposium. Proceedings of the Nutrition Society 52, 189-199.

Smith, A. P. \& Kendrick, A. M. (1992). Meals and performance. In Handbook of Human Performance. vol. 2, Health and Performance, pp. 2-23 [A. P. Smith and D. M. Jones, editors]. London: Academic Press.

Smith, A. P., Leekam, S., Ralph, A. \& McNeill, G. (1988). The influence of meal composition on post-lunch performance efficiency and mood. Appetite 10, 195-203. 
Smith, A. P. \& Miles, C. (1986). Acute effects of meals, noise and nightwork. British Journal of Psychology 77, 377-387.

Smith, A. P., Rusted, I. M., Savory, M., Eaton-Williams, P. \& Hall, S. R. (1991). The effects of caffeine, impulsivity and time of day on performance, mood and cardiovascular function, Journal of Psychopharmacology 5, 120-128.

Spring, B., Chiodo, J. \& Bowen, D. J. (1987), Carbohydrates, tryptophan, and behavior; a methodological review. Psychological Bulletin 102, 234-256.

Spring, B., Maller, O., Wurtman, J., Digman, L. \& Cozolino, L. (1983). Effects of protein and carbohydrate meals on mood and performance: interactions with sex and age. Journal of Psychiatric Research 17, 155-167.

Stacher, G., Bauer, H. \& Steinringer, H. (1979). Cholecystokinin decreases appetite and activation evoked by stimuli arising from the preparation of a meal in man. Physiology and Behavior 23, 325-331.

Steele, C. M. \& Josephs, R. A. (1990). Alcohol myopia: its prized and dangerous effects. American Psychologist 45, 921-933.

Teff, K. L., Young, S. N. \& Blundell, J. E. (1989). The effect of protein or carbohydrate breakfasts on subsequent plasma amino acid levels, satiety and nutrient selection in normal males. Pharmacology, Biochemistry and Behavior 34, 829-837.

van der Stelt, O. \& Snel, J. (1993). Effects of caffeine on human information processing. In Caffeine, Coffee and Health, pp. 291-316 [S. Garattini, editor]. New York: Raven Press.

Wells, A. S. \& Read, N. W. (1994). Meal composition and post-prandial mood and alertness: the influence of the fat and energy content of meals ingested mid morning and at lunch time. Proceedings of the Nutrition Society (In the Press).

Wenk, G. L. (1989). An hypothesis on the role of glucose in the mechanism of action of cognitive enhancers. Psychopharmacology 99, 431-438.

Wurtman, R. J., Hefti, F. \& Melamed, E. (1981). Precursor control of neurotransmitter synthesis. Pharmacological Reviews 32, 315-335.

Wurtman, R. J. \& Wurtman, J. J. (1992). The use of carbohydrate-rich snacks to modify mood state: a factor in the production of obesity. In The Biology of Feast and Famine, Relevance to Eating Disorders, pp. 151-156 [G. H. Anderson and S. H. Kennedy, editors]. San Diego: Academic Press.

Young, S. N. (1991). Some effects of dietary components (amino acids, carbohydrate, folic acid) on brain serotonin synthesis, mood and behaviour. Canadian Journal of Physiology and Pharmacology 69, 893-903. 